\title{
Study on NVOCs Concentration Characteristics by Season, Time and Climatic Factors: Focused on Pinus densiflora Forest in National Center for Forest Therapy
}

\author{
Jin Hwa Park, Suk Hee Park, Hyo Jung Lee, Jae Woo Kang, Kyoung Min Lee, and Poung Sik Yeon* \\ National Center for Forest Therapy, Yeongju 36043, Korea
}

\begin{abstract}
Forest therapy refers to activities that enhance the body's immune system and improve health by utilizing various elements such as scents and landscapes. Forest therapy is expected to be used along with modern medical treatments for physical and mental illnesses. Natural volatile organic compounds (NVOCs) are one of the important resources of forest therapy. This study compared the concentration of NVOCs by season and time, and compared the correlation between NVOCs and climatic factors (temperature, humidity and wind speed). Air samples and climatic data were measured once a month in Pinus densiflora forest in the National Center for Forest Therapy from June 2017 to May 2018 and five components such as $\alpha$-Pinene, $\beta$-Pinene, Camphene, Limonene, and Camphor were analyzed for NVOCs. The concentration of NVOCs by season is highest in summer, followed by spring, fall, and winter. The ratio of $\alpha$-Pinene among NVOCs was high in summer. The NVOCs concentration over time was highest at 5 p.m. and lowest at 8 a.m. The correlation between the climatic factors and the NVOCs concentration was statistically significant for all three factors: temperature, humidity, and wind speed. The correlation was positive between NVOCs and temperature or humidity, whereas it was negative between NVOCs and wind speed. This study concludes that forest therapy using NVOCs can be more effective when the temperature and humidity within the stands are high and the wind speed is low to maximize forest healing effects.
\end{abstract}

Keywords: $\alpha$-Pinene, phytoncide, Pinus densiflora

\section{Introduction}

Because of the rapid industrialization since the 1960s, most of the agricultural workforce shifted to industrial workforce in South Korea. As a result, the Korean economy has achieved economic growth unprecedented in history, and is shared as a typical case of economic development. However, people today are suffering physical stress due to work overload and mental stress due to severance from nature, which are side effects of industrialization and urbanization. Although not directly suffering from diseases, a rapidly increasing population is in subhealth (such as chronic fatigue and anxiety) that may develop into a certain disease anytime (Park, 2011). In addition to the therapeutic methods of modern medicine, forest therapy is also expected to be applied to such physical and mental 
illnesses of people today (Park, 2010).

Due to the recent policy of the five-day workweek and 52-hour workweek system, people's demand for forests is constantly increasing. While the form of recreation in the past has been just relaxing in the forest, now it is being expanded into a more active sense of forest therapy (Lee et al., 2015), and promotion of health through forest therapy is receiving national attention (Joung et al., 2015a). According to Article 2, paragraph 4 of the Forestry Culture and Recreation Act, "forest therapy" means immune-strengthening and health-promoting activities, which utilize a variety of elements of the forest, including scents and scenic views. To meet the national demands, the Korea Forest Service is operating one National Center for Forest Therapy, four SoopCheWons, three healing forests, and one forest experience center for little children as of 2018. The healing environment items among the selection evaluation critera for healing forests include natural volatile organic compounds (NVOCs) and anion concentration (Korea Forest Service, 2018), and recently more and more studies are using NVOCs for therapeutic purposes (Kim et al., 2017; Joung et al., 2015b).

NVOCs refer to essential oils generated and released by plants to protect themselves from the attacks of insects or microorganisms (Cha, 1995; Kang, 2003). Yatagai (2008) discovered that NVOCs can selectively kill specific bacteria and protect the plants, but are also not harmful when absorbed by human body. The effects of NVOCs include antibacterial, insect repellent, deodorizing, etc. Direct effects on the human body include activation of physiological functions, relief of tension and excitement, and stabilization of mind and body, as well as increase of immunity by activating natural healing effect (Shin, 2009; Kang, 2005). Among the main components of NVOCs, $\alpha$-Pinene is effective for muscle pain, cold, mental fatigue and blood circulation, and camphene is effective for menopausal disorder, lack of mother's milk, dermatitis, phlegm, digestion and detoxification (Park et al., 2010; Kang, 2003). Moreover, limonene is effective for cold, blood circulation, hypertension and depression (Park et al., 2010).

This study analyzed the generation characteristics of NVOCs that are typical healing factors of forests by season and time, and provides the baseline data to maximize forest therapy effects by determining the correlation with climatic factors.

\section{Research Methods}

\section{Study area}

This study was conducted at Masil Healing Forest Path that is the main forest path of the National Center for Forest Therapy located in Yeongju, Gyeongsangbuk-do (Figure 1). The study area is dominated by Korea's typical tree species Pinus densiflora, and the result of $20 \mathrm{~m} \times 20 \mathrm{~m}$ sample plot survey, the place has the average height of $17.3 \mathrm{~m}$, average diameter at breast height of $46 \mathrm{~cm}$, age class of $\mathrm{V}$, and good afforestation.

\section{Measurement items}

The selected items were five components ( $\alpha$-Pinene, $\beta$-Pinene, Camphene, Limonene, Camphor) with the highest concentration among the NVOCs used in the analysis of phytoncide ( $\alpha$-Pinene, $\beta$-Pinene, Camphene, Limonene, Camphor). To analyze the correlation between climatic factors and NVOCs generation amount, the auto weather system (Whion, Korea) was used to examine the temperature, humidity, and wind speed. They were measured once a month for a year from June 2017 to May 2018. The results were compared by season such as summer (June-August), fall (September-November), winter (December-February) and spring (March-May), and by time zone such as 8-9 a.m., noon-1 p.m., and 5-6 p.m. 


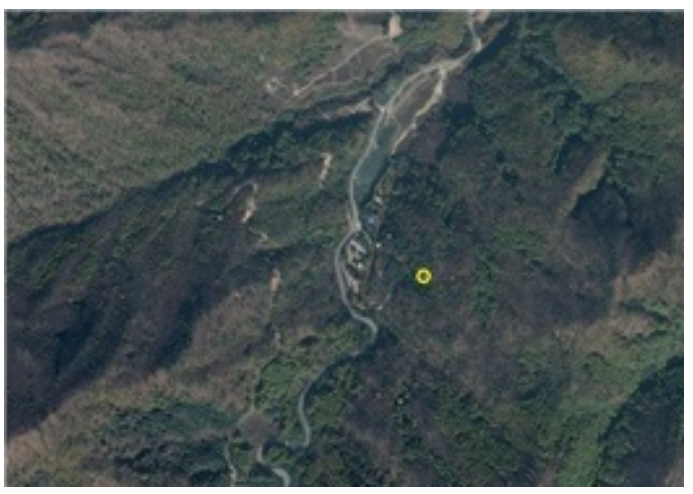

(A)

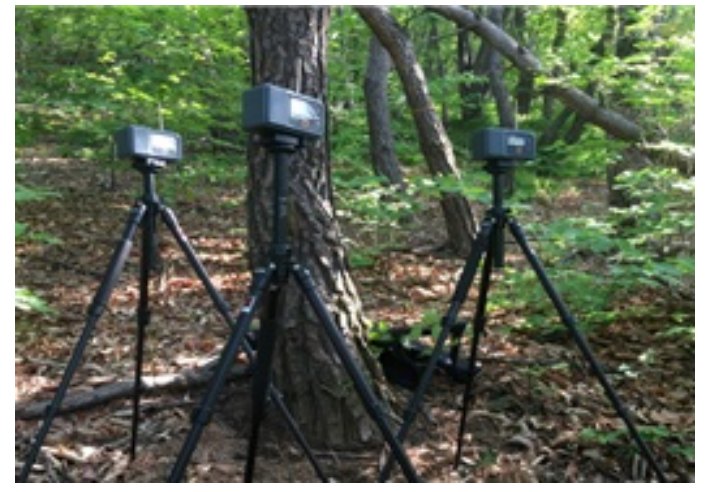

(B)

Figure 1. Satellite photograph of sampling site (A) and picture of three sampling pumps to measure air (B).

\section{Measurement method}

For sample measurement, the absorbent tubes (Tenax TA, KNR, Korea) conditioned for 2 hours at $310^{\circ} \mathrm{C}$ the day before measurement were used. Three sampling pumps (MP- $\Sigma 30 K N$ II, Sibata, 2016, Japan) were installed horizontally at $1.5 \mathrm{~m}$ above ground, and total $9 \mathrm{~L}$ of air was measured for 60 minutes at the speed of $150 \mathrm{ml} / \mathrm{min}$ after connecting the absorbent tubes. The sample measuring person used disposable polyethylene gloves and antibacterial mask to prevent artificial errors. The absorbent tubes after measurement were sealed and stored at low temperature, and one absorbent tube was used as a blank tube without sampling to reduce the error of analysis results. The climatic factors were measured at 5-minute intervals for total 10 hours from 8 a.m. to 6 p.m. after installing the auto weather system horizontally at the study area, and the mean value was used as the result.

\section{Analysis method}

The measured absorbent tubes were analyzed using the gas chromatography/ mass spectrometer (GC/MS, Shimadzu, Japan) with a thermal desorption device (TD-20, Shimadzu, Japan). NVOCs in the tubes undergo thermal desorption for 15 minutes by $30 \mathrm{ml}$ per minute at $280^{\circ} \mathrm{C}$ through the automatic thermal desorption system (TDS), concentrated in the cold trap set at $-10^{\circ} \mathrm{C}$, and injected into GC through thermal desorption once more at $280^{\circ} \mathrm{C}$. NVOCs are detected from the injected sample through MS.

For the correlation between climatic factors and phytoncide generation amount, bivariate correlation analysis was conducted using IBM SPSS ver. 24.0 and the result was presented through a scatter plot.

\section{Results and Discussion}

\section{NVOCs concentration by season}

Figure 2 shows the distribution of NVOCs concentration by season. The concentration was highest in summer with $187.82 \mathrm{pptv}$, followed by spring, fall and winter. Spring was $97.31 \mathrm{pptv}$, fall $77.91 \mathrm{pptv}$ and winter $25.61 \mathrm{pptv}$. This result is consistent with previous studies proving that NVOCs increase in summer when the temperature is high (Park et al., 2010; Hakola et al., 2000). This study also showed the highest temperature $\left(25.65^{\circ} \mathrm{C}\right)$ and humidity $(51.52 \%)$ in summer when measuring the temperature and humidity of the study area using the auto weather system (Table 1).

Figure 3 shows the ratio of the main components of NVOCs ( $\alpha$-Pinene, $\beta$-Pinene, Camphene, Limonene, Camphor) in 


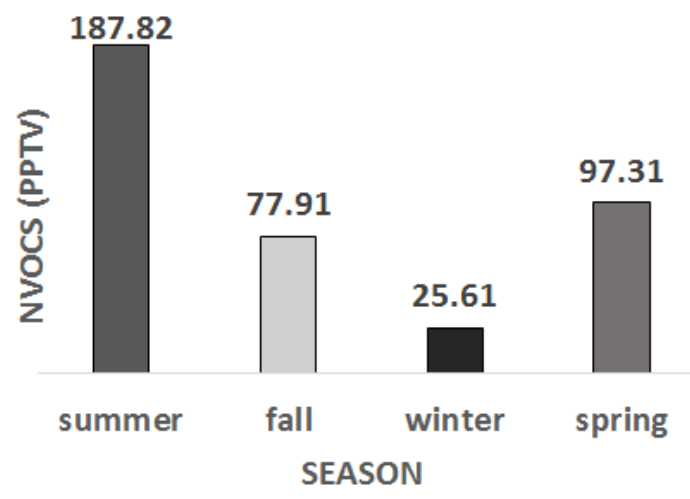

Figure 2. Natural volatile organic compounds(NVOCs) concentration according to season.

Table 1. Monthly temperature and humidity from June 2017 to May 2018

\begin{tabular}{ccccccccccccc}
\hline & Jun & Jul & Aug & Sept & Oct & Nov & Dec & Jan & Feb & Mar & Apr & May \\
\hline Temperature $\left({ }^{\circ} \mathrm{C}\right)$ & 23.74 & 26.20 & 27.00 & 21.43 & 11.60 & 7.57 & -4.19 & 0.81 & 4.67 & 1.87 & 20.57 & 17.87 \\
Humidity $(\%)$ & 27.31 & 52.55 & 74.70 & 52.72 & 36.51 & 16.47 & 4.78 & 25.26 & 9.00 & 39.44 & 20.25 & 56.56 \\
\hline
\end{tabular}

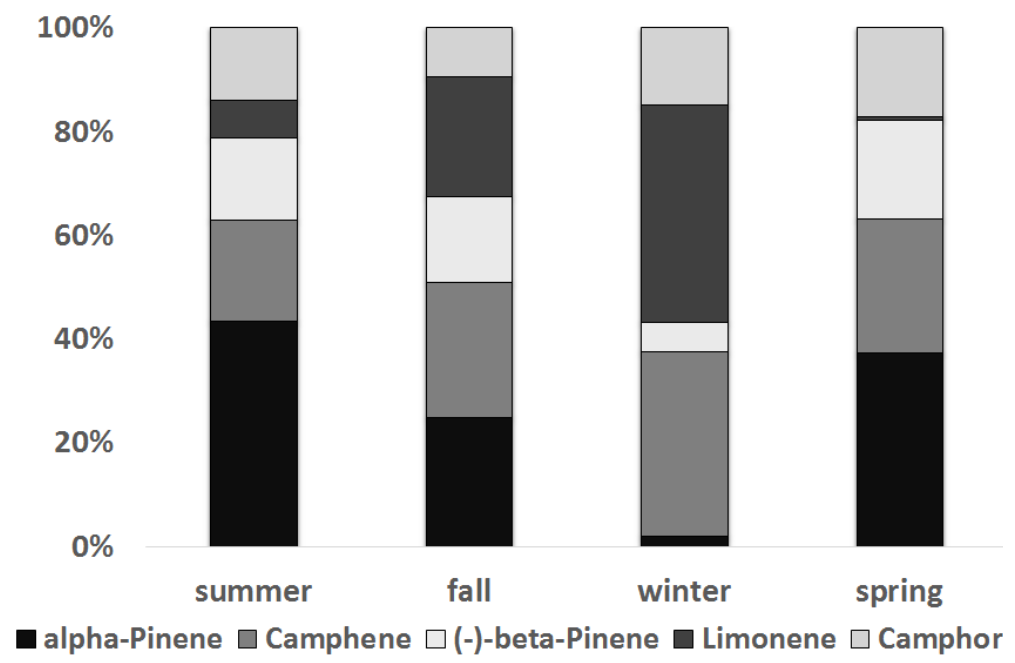

Figure 3. Natural volatile organic compounds(NVOCs) composition ratio according to season.

the study area. The ratio of $\alpha$-Pinene was highest (43.36\%) in summer, followed by spring (37.32\%) and fall (24.74\%). This is similar to the study by Kim et al. (2002) stating that the composition ratio of $\alpha$-Pinene was highest in the 32-year-old Pinus densiflora forest, and the study by Park et al. (2013a) proving that the composition ratio of $\alpha$-Pinene was highest as a result of analyzing the composition ratio of phytoncide in the coniferous forest at a trail in Ulsan.

\section{NVOCs concentration by time}

Figure 4 shows the mean of NVOCs concentration by time measured for an hour at 8 a.m., noon, and 5 p.m. It was 79.37 pptv at 8 a.m., 104.24 pptv at noon, and 107.87 pptv at 5 p.m. Previous studies on NVOCs concentration by time include 


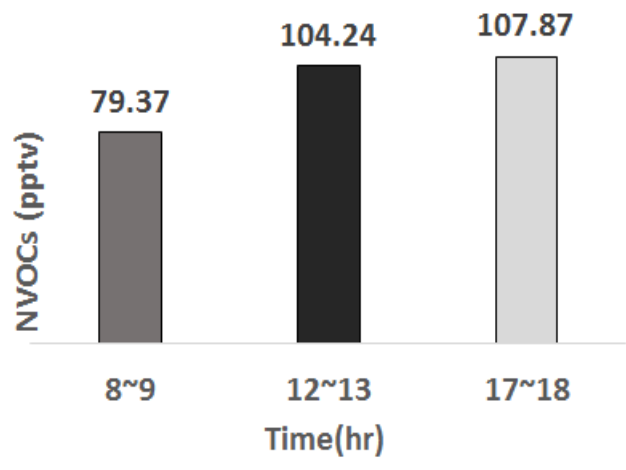

Figure 4. NVOCs concentration according to time.

Table 2. Correlation between NVOCs and climatic factors

\begin{tabular}{cccccc}
\hline & & NVOCs & Temperature & Humidity & Wind speed \\
\hline \multirow{3}{*}{ NVOCs } & $\mathrm{r}$ & 1 & $.615^{* * *}$ & $.611^{* * *}$ & $-.602^{* *}$ \\
& $p$ & & .000 & .000 & .000 \\
& $\mathrm{~N}$ & & 36 & 36 & 36 \\
${ }^{* *} p<.01$ & & & &
\end{tabular}

a study claiming that phytoncide concentration increases in daytime when the temperature and solar radiation are high (Yatagai et al., 1995), and a study proving that phytoncide concentration is high at sunrise and sunset when the atmosphere is stabilized, but concentration decreases in the daytime due to the influence of decomposition and diffusion by photochemical reaction (Kang, 2003). Recently, Park et al. (2013b) studied phytoncide characteristics according to the change of time in Ulsan and found that phytoncide concentration is highest at sunrise and in the morning, decreases at noon, and increases once again after sunset.

This study performed the measurements at 8 a.m., noon, and 5 p.m. when there is walking or a forest therapy program instead of sunrise or sunset, thereby showing results that are not consistent with the trend of previous studies. It is necessary to conduct additional research with more subdivided measurement intervals from sunrise to sunset.

\section{Correlation between climatic factors and NVOCs}

Table 2 shows the result of analyzing the correlation between climatic factors and NVOCs. The positive correlation is higher if the correlation coefficient(r) is closer to 1 , and the negative correlation is higher if it is closer to -1 . The correlation between temperature and NVOCs turned out to be statistically significant $(p<.01)$, and the correlation coefficient was .615 and thus the correlation was positive (Figure 5A). This is consistent with the study (Park et al., 2013a) that the amount of NVOCs increases along with the temperature, and the biological activity of trees increases with the effect of high temperature and humidity in summer and transpiration in the stomata becomes more active, thereby increasing the amount of phytoncide.

The correlation between humidity and NVOCs also turned out to be statistically significant $(p<.01)$, and the correlation coefficient was .611 and thus the correlation was positive (Figure 5B). NVOCs turned out to be higher when the humidity is high, which is consistent with the study (Kim and Jeon, 2012) that the amount generated from the trees is not great when humidity is high, but gas exchange in the atmosphere is not active and thus NVOCs may turn out to be high. 


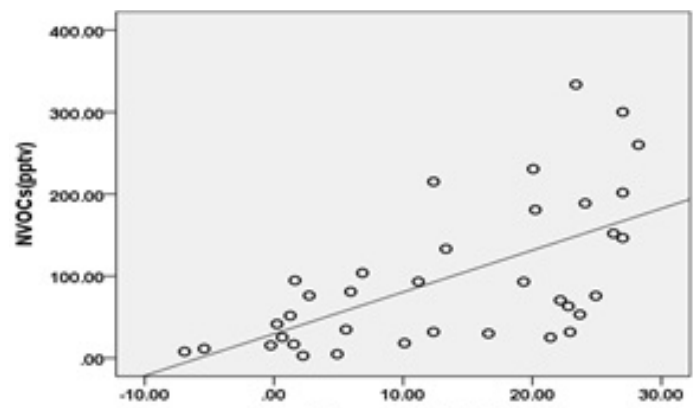

(A)

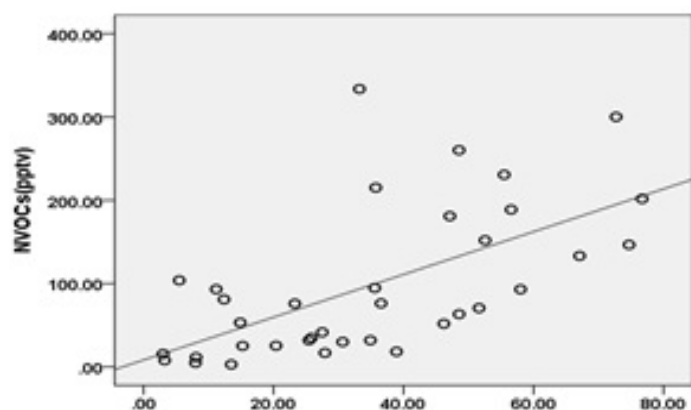

(B)

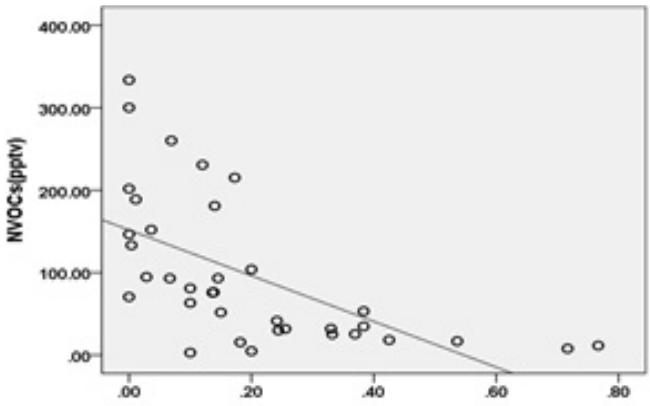

(C)

Figure 5. Correlation graph between NVOCs and climatic factors; temperature (A), humidity (B), and wind speed (C).

The correlation between wind speed and NVOCs also turned out to be statistically significant $(p<.01)$, and the correlation coefficient was -.602 and thus the correlation was negative (Figure 5C). This is consistent with the result by Yatagai et al. (1995) and Kim et al. (2017) investigating the Pinus densiflora forest in Gangwon-do, which proved that NVOCs concentration and wind speed show a negative correlation. Phytoncide generated from the trees is low because it is widespread instead of staying in the stands when the wind is strong.

\section{Conclusion}

This study compared the NVOCs concentration by season and time in the healing forest path dominated by Pinus densiflora in the National Center for Forest Therapy, and provides baseline data to maximize the forest therapy effects by comparing the correlation between NVOCs concentration and climatic factors (temperature, humidity, wind speed). The average concentration of NVOCs by season was highest in summer with 187.82 pptv, followed by spring, fall and winter. Spring was $97.31 \mathrm{pptv}$, fall $77.91 \mathrm{pptv}$ and winter $25.61 \mathrm{pptv}$. The mean concentrations of NVOCs by time were 79.37 pptv at 8 a.m., $104.24 \mathrm{pptv}$ at noon and $107.87 \mathrm{pptv}$ at $5 \mathrm{p}$.m. This study performed the measurements at 8 a.m., noon, and 5 p.m. when there is walking or a forest therapy program instead of sunrise or sunset, thereby showing results that are not consistent with the trend of previous studies proving that NVOCs concentration is high at sunrise and sunset when the atmosphere is stabilized. The correlation between climatic factors and NVOCs was statistically significant in all three factors (temperature, humidity, wind speed) with $p<.01$. The correlation was positive for temperature and humidity with the coefficient of .615 and .611, whereas it was negative for wind speed with the coefficient of -.602. This result indicates that forest therapy using NVOCs is more effective when the temperature and humidity within the stands are high and the wind speed is low. However, temperature and humidity that are too high may rather directly increase the thermal index and discomfort index of the human body, which is why additional research is required. 


\section{References}

Cha, Y.J. 1995. Forest bathing, trip to the forest: Healthy way of forest bathing while understanding nature. Seoul, Korea: Donghaksa Publishing.

Hakola, H., T. Laurila, J. Rinne, and K. Puhto. 2000. The ambient concentration of biogenic hydrocarbons at a northern European, boreal site. Atmos. Environ. 34(29-30):4971-4982. DOI:10.1016/S1352-2310(00)00192-8

Joung, D.W., D.G. Yeom, G.W. Kim, and B.J. Park. 2015a. Physiological and psychological relaxing effects of viewing the scenery in the Jangseong Healing Forest. J. Korean Soc. People Plants Environ. 18(5):429-435

Joung, D.W., G.W. Kim, Y.H. Choi, H.J. Lim, S.J. Park, J.M. Woo, and B.J. Park. 2015b. The prefrontal cortex activity and psychological effects of viewing forest landscapes in autumn season. Int. J. Environ. Res. Public Health 12(7):7235-7243. DOI:10.3390/ijerph120707235

Kang, H.Y. 2003. The Secret of phytoncide. Seoul. Korea: YeoksaNet publisher.

Kang, H.Y. 2005. Immune system and phytoncide. For. J. 4:76-80. Retrieved from http://www.nfcf.or.kr

Kim, G.W., C.H. Park, S.G. Lee, D.W. Joung, J.D. Lee, and B.J. Park. 2017. Development of a prediction model for NVOCs concentration with changing microclimate in Pinus Densiflora Forest. J. Korean Inst. For. Recreat. 21(3):11-21.

Kim, J.C., J.H. Hong, M.C. Joo, J. Jun, and K.J. Kim. 2002. Composition of monoterpene by tree age of Pinus densiflora. J. Environ. Res. (Printed in Dongshin University) 7(1):77-87.

Kim, K.W. and K.S. Jeon. 2012. Forest healing (2nd ed.). Seoul, Korea: Kookmin University Press.

Korea Forest Service. 2018. Public announcements for the applications for research contract (No. 2018-71). Daejeon, Korea: Author.

Lee, Y.K., J.S. Woo, S.R. Choi, and E.S. Shin. 2015. Comparison of phytoncide (monoterpene) concentration by type of recreational forest. J. Environ. Health Sci. 41(4):241-248. DOI:10.5668/JEHS.2015.41.4.241

Park, B.J. 2010. Experimental approach of therapeutic effect of forest recreation activities: Focused on viewing and walking in forest environments. Doctoral dissertation, Chungnam University, Daejeon, Korea.

Park, B.J. 2011. Present and future of forest therapy. Proc. Korean Soc. Environ. Ecol. 21(2):3-5.

Park, D.K., P.S. Shin, C.Y. Kim, O.K. Kweon, and T.G. Suk. 2010. Distribution characteristics of phytoncide (monoterpene) in the recreation forest in Chungchenbukdo. The Annual Report of Chungchenbuk-do Institute of Health \& Environ. 19:87-115.

Park, H.J., B.G. Yu, S.H. Park, J.Y. Lee, Y.S. Hahm, S.W. Jeong, K.Y. Byeon, S.H. Kim, I.S. Jung, and M.L. Lee. 2013 a. Study on seasonal variation characteristics of forest phytoncide in Ulsan metropolitan trails. J. Environ. Sci. Int. 22(11):1415-1419. DOI:10.5322/JESI.2013.22.11.1415

Park, H.J., B.G. Yu, S.H. Park, J.Y. Lee, Y.S. Hahm, S.W. Jeong, K.Y. Byeon, H.H. Lee, S.H. Choi, J.M. Son, and M.L. Lee. 2013b. Study on timely characteristics of forest phytoncide in Ulsan metropolitan trails. J. Environ. Sci. Int. 22(11):1451-1456. DOI:10.5322/JESI.2013.22.11.1451

Shin, W.S. 2009. Psychological and physiological health effects of forests. For. J. 7:37-39. Retrieved from http://www.nfcf.or.kr

Yatagai, M. 2008. What is phytoncide (B.H. Hwang, Trans.). Chuncheon, Korea: Kangwon National University Press.

Yatagai, M., M. Ohira, T. Ohira, and S. Nagai. 1995. Seasonal variations of terpene emission from tree and influence of temperature, light and contact stimulation on terpene emission. Chemosphere 30(6):1137-1149. DOI:10.1016/0045-6535(95)00006-T 